\title{
Stress: Friend or Enemy?
}

\author{
Junqian Ma \\ Faculty of Education, Clayton Campus, Monash University, \\ Wellington Road Clayton, Victoria 3800, Australia \\ Email: junqianma@gmail.com
}

\section{Doi:10.5901/jesr.2014.v4n6p275}

\begin{abstract}
The question of whether stress positively or negatively influences people's life is controversial. Based on previous studies, this paper argues that stress can be categorized into different types and whether stress is friend or enemy to people is determined by objective conditions and subjective factors including temperament type, personality and values. This study provides implications for future researches to view stress from a comprehensive and dialectical perspective.
\end{abstract}

Keywords: stress, stress type, stress cause, stress influence

\section{Introduction}

The term "stress", which was first appeared in psychological abstract in 1944 (Jones, Bright, \& Clow, 2001), is recently used by common people in a wide range of ways to describe their mental state or current situation, etc.

In an academic sense, stress can be defined from both biological and psychological perspective, and there is no unanimous definition for it among researchers. One of the controversies focuses on whether stress is positive, negative or neutral. Some regard stress as a source of negative conditions experienced by people and a basis for headaches, back pain and poor performance (Robert-Macomb \& Young, 2012), in contrast, some consider stress as positive process rather than a threat which leads to positive outcomes (Folkman \& Moskowitz, 2000). Moreover, in the TED speech of How to make stress your friend by Kelly McGonigal, whether stress brings benefits or harms relies on people's view on it.

The topic of "whether stress is our friend or enemy" is meaningful in that it guides us to a wider and deeper scope of stress as well as provides us with efficient solutions to deal with stress issues. This paper will pay attention to what causes stress, in what circumstances stress is friend or enemy (positive or negative), and how we can transform stress into opportunities.

\section{Stress Types and Causes}

In order to give an insight into whether stress is positive or negative, it is essential to study the stress types and causes so that we can research into the issue from a deep-level. In this part, different classifications of stress types according to three different theories and the stress causes based on stress types and Weiner's Attribution Theory will be presented.

According to the certain objects people worry about, stress can be categorized into four on the basis of the work of Albrecht (2010): Time stress (worry about time), Anticipatory stress (worry about the future), Situational stress (scared by the situation that you have no control over), and Encounter stress (afraid of meet or communicate with people). From the perspective of duration, psychologists listed three types of stress: Acute stress, which is short-lived but most intense; Acute Episodic Distress, which refers to a situation where one stressful event comes after another; and Chronic Distress, the type of stress that arises out of long-lasting events and circumstances beyond your control. By looking into the influences and results, stress can be defined as Eustress (Good Stress) that is deemed healthful or giving one the feeling of fulfillment and Distress (Bad Stress) which causes pain, anxiety, or sorrow.

Based on the stress types presented above and the Attribution Theory established by Weiner (1986, pp. 128-154), stress causes are split into three following aspects: stable or unstable, external or internal, and controllable or uncontrollable. By connecting these three dimensions, stress causes can be divided into eight which are shown below in the table and some examples are listed follow each stress cause. 


\begin{tabular}{|c|c|c|c|c|c|c|c|}
\hline \multicolumn{4}{|c|}{ External } & \multicolumn{3}{c|}{ Internal } \\
\hline \multicolumn{2}{|c|}{ Controllable } & \multicolumn{2}{|c|}{ Uncontrollable } & \multicolumn{2}{c|}{ Controllable } & \multicolumn{2}{c|}{ Uncontrollable } \\
\hline Stable & Unstable & Stable & Unstable & Stable & Unstable & Stable & Unstable \\
\hline Final exam & Promotion & Work time change & Car accident & Learn skills & Get high score & Jet lag & Disease \\
\hline
\end{tabular}

\section{Friend or Enemy?}

The possibility for certain stress to be positive or negative is not random. Based on the theories introduced in the preceding part of the paper, the certain conditions which make stress to be positive or negative can be found out. The following analyses are structured into objective and subjective perspective to identify in what circumstance stress results in benefit or harm.

\subsection{Objective conditions}

Whether stress is a friend or an enemy primarily depends on what kind of occasions or circumstance people encounter. Viewing this question from the angle of stress type and Attribution Theory discussed above, the table below gives information about which kind of objective situation lead to a positive or negative effect. The " $\star$ " is the representative of stress possibly as friend, while the " $\boldsymbol{\Delta}$ "is on behalf of stress possibly as enemy.

\begin{tabular}{|c|c|c|c|c|c|c|c|}
\hline \multicolumn{4}{|c|}{ External } & \multicolumn{4}{|c|}{ Internal } \\
\hline \multicolumn{2}{|c|}{ Controllable } & \multicolumn{2}{|c|}{ Uncontrollable } & \multicolumn{2}{|c|}{ Controllable } & \multicolumn{2}{|c|}{ Uncontrollable } \\
\hline Stable & Unstable & Stable & Unstable & Stable & Unstable & Stable & Unstable \\
\hline$\star$ & & & $\Delta$ & $\star$ & & & $\Delta$ \\
\hline
\end{tabular}

It is hypothesized that no matter external or internal, controllable and stable things (such as a test or a coming holiday) make people more optimistic and less stressful than uncontrollable things because the situation they meet is within the control and foreseeable, so that they feel safer and more confident. Moreover, within such situation, people tend to take active actions instead of sitting still because the issues are seemed soluble so that they can not only successfully solve the problem, but also gain the experience and sense of accomplishment. Therefore, in such situation, people benefit.

On the contrary, uncontrollable and unstable matters (such as car accident or injury), which are always haphazard and happened in a sudden, are likely to lead people to hopeless situation due to the difficulties of predicting as well as solving them. When the problems emerge, people incline to avoid them rather than deal with them which let the situation even worse and in turn make people more stressed and desperate. Therefore, in a long run, if this vicious circle continues and the stress last, it will definitely get people's life into mess or even do harm to their health physically and mentally.

In general, the stress caused by different issues with certain characteristics brings about different results---positive or negative. It can be concluded that the stress resulting from controllable and stable matter is more likely to benefit people. Conversely, the stress generating from uncontrollable and unstable matters is possible to have adverse impact on people.

\subsection{Subjective factors}

Apart from the objective conditions, subjective factors such as temperament type, personality, personal value are more significant in determining the effect of certain stress. In the following part, the three subjective factors and their connections with the effects of stress will be discussed.

\subsubsection{Temperament type}

The term "Temperament" refers to aspects of an individual's personality which are regarded as innate rather than acquired. The temperament theory is originated from the work by the Greek physician Hippocrates who believed human emotions and behaviors were caused by body fluids which are blood, yellow bile, black bile, and phlegm. Based on his theory, a great number of related theories have been proposed. Among them, the most popular and accepted one classifies the human temperaments into four: Sanguine, Choleric, Melancholic and Phlegmatic. People with different 
innate temperaments behave differently in the same situation and respond differently to the same issue. As a result, the stress generating from the same thing can have varied meanings and impacts on different people.

People with sanguine temperament are sociable, energetic and optimistic. When they face a problem and get stressed, they tend to view it in an optimistic way and seek comfort from their friends. Even they lost in the worst situation and suffer great stress; they can get out of it faster. Like sanguine people, the choleric people are energetic and optimistic but more aggressive, ambitious and impulsive. They are more likely to get rid of the stress by expressing and releasing them so that they can also deal with the stress easily.

The phlegmatic and melancholic temperaments are regarded as introverted. Compare with these two, phlegmatic people are relaxed and quiet, ranging from warmly attentive to lazily sluggish, while melancholic are easier to get depressed and pessimistic. Unlike sanguine and choleric people, phlegmatic and melancholic people seldom express their feelings or turn to help, but always suppress their sense of stress inside so they are more likely to be negatively influenced by stress physically and mentally.

Therefore, the temperament type influences people's way to deal with stress to some degree. People with sanguine and choleric temperaments tend to face stress in an optimistic way, on the contrary, people with phlegmatic and melancholic temperaments prone to suffer the stress. However, this is just a general tendency of certain types of people to face stress. Whether stress will be positive or negative is related with more other factors.

\subsubsection{Personality}

Different from temperaments, an individual's personality is established by education and social influence rather than inborn, which is the particular combination of emotional, attitudinal, and behavioral response patterns of an individual. People with different personality traits respond differently to stress.

Based on the theory of ego-control and ego-resiliency (Block \& Block, 1980), personality is categorized into three: resilients, overcontrollers, and undercontrollers (Meeus, Van de Schoot, Klimstra, \& Branje, 2011). Resilients who have high levels of ego-resiliency and moderate levels of ego-control adapt to stress easily and usually take active actions to deal with the stress. Over controllers and under controllers who have low levels of ego-resiliency are not good at adapting to stress. Furthermore, over controllers who are in high levels of ego-control tend to control their feeling of stress or their emotions while under controllers who are in low levels of ego-control tend to be fragile when facing stress. Therefore, from this perspective, stress is possible to be positive for people who are resilient.

Another personality theory is called "Jung's model of Typology" which differentiates two personality attitudesintroversion and extroversion, and four modes of orientation-thinking, sensation, intuition and feeling (Sharp, 1987). According to correlation analysis, the tendency to worry is considerably related to Introversion and Feeling dimensions (Ragozzino \& Kelly, 2011). In this sense, individuals of Introversion and Feeling type are more vulnerable to stress and are easily negatively influenced by stress. Moreover, the work of Chanin (1984) which focuses on the relationship between Jung's Personality Dimensions and Conflict-Handling Behavior shows that individuals of feeling type tend to handle conflict through compromising and accommodating whereas those of thinking type are more often to compete or collaborate, which also indicate the different ways of different personality types of individuals to deal with stress.

In sum, individuals with different personalities respond to the same issues or stress differently due to their diverse emotional, attitudinal, thinking and behavioral patterns. Generally, resilient and extroverted people can easily manage stress whereas under controlled, introverted and feeling type individuals are sensitive to stress and usually have difficulties in dealing with them.

\subsubsection{Value}

Value refers to personal views on external world that provides internal reference for what is important or beneficial and what is useless or detrimental, which further generate behavior (Rokeach, 1973) and help solve problems. When facing stress, personal value plays an essential role in determining what attitude they hold toward it and what method they use to handle it.

According to the experiment illustrated in the TED speech of How to make stress your friend by Kelly McGonigal, people who experience a lot of stress had a $43 \%$ increased risk of dying, but that was only true for the people who also believe that stress is harmful for their health. To be specific, the people who have much stress but did not view stress as harmful were no more likely to die. In fact, they have the lowest risk of dying.

To conclude, personal values can influence the way of stress affect people. The one who believe that stress do 
harm to his life, he will negatively influenced by it. Reversely, the one who think that stress is a challenge instead of a tragedy, he will benefit from it.

\section{Conclusion}

It is difficult to define stress as positive or negative from a sole perspective. Instead, whether it is friend or enemy lies on lots of factors which are structured into objective conditions and subjective factors. Specifically, the effect of stress on a person depends on the attribution of the issue itself, personal temperament, personality and value. Besides, these factors are interconnected with each other in determining whether certain stress will be beneficial or detrimental to people.

In addition, although certain stress tend to be negative at the beginning, people can still take active actions to turn it to positive opportunities. The most convenient and efficient way is to hold an optimistic and positive view on stress. It is important to learn that it's not the event itself but usually people's thoughts about the event when they are trying to manage stress influence people physically and mentally. In addition, more methods to manage stress are suggested by scientists, like exercise, cut down caffeine in drinks, organize time, seek professional help, use relaxation techniques as mediation, massage or yoga, etc.

To sum up, this paper has shown the stress types and causes, analyzed the objective and subjective conditions which determine the effect of stress (positive or negative) and also suggested several ways to manage stress.

\section{References}

Albrecht, K. (2010). Stress and the Manager. New York: Simon and Schuster.

Block, J. H., \& Block, J. (1980). Role of ego-control and ego-resiliency in the organization of behavior. In W. A. Collins (Ed.), Development of cognition, affect, and social relations (pp. 39-101). Hillsdale, N.J. : L. Erlbaum Associates

Chanin, M. N. (1984). A Study of the Relationship between Jungian Personality Dimensions and Conflict- Handling Behavior. Human Relations, 37(10), 863-879.

Folkman, S., \& Moskowitz, J. T. (2000). Stress, positive emotion, and coping. Curr. Dir. Psychol., 9(4), 115-118.

Jones, F., Bright, J., \& Clow, A. (2001). Stress : myth, theory, and research. New York: Prentice Hall.

Meeus, W., Van de Schoot, R., Klimstra, T., \& Branje, S. (2011). Personality Types in Adolescence: Change and Stability and Links With Adjustment and Relationships: A Five-Wave Longitudinal Study. Dev. Psychol., 47(4), 1181-1195.

Ragozzino, R. L., \& Kelly, W. E. (2011). Typing the worrier: relationship between worry and Jung's personality types. Education, 131(4), 791.

Robert-Macomb, J. J., \& Young, B. O. (2012). The physiology of Stress. In K. L. Goodheart, J. R. Clopton \& J. J. Robert-McComb (Eds.), Eating disorders in women and children : prevention, stress management, and treatment (pp. 101-124). Boca Raton, FL: CRC Press.

Rokeach, M. (1973). The nature of human values. New York: Free Press.

Sharp, D. (1987). Personality types : Jung's model of typology. Toronto, Canada: Inner City Books.

Weiner, B. a. (1986). An Attributional Theory of Motivation and Emotion: New York: Springer. 